\title{
The solubility of sebacic acid in subcritical water using the response surface methodology
}

\author{
Erdal Yabalak • Özkan Görmez • Belgin Gözmen • \\ Ahmet Murat Gizir
}

Received: 22 August 2014/Accepted: 8 December 2014/Published online: 9 January 2015

(C) The Author(s) 2015. This article is published with open access at Springerlink.com

\begin{abstract}
The solubility of sebacic acid in subcritical water was investigated. Response surface methodology was used to study the combined effects of the different parameters such as temperature, static and dynamic time to optimize the process conditions for the maximum solubility of sebacic acid. Solubility results of sebacic acid were observed to be highly correlated with quadratic model according to analysis of variance. The solubility of sebacic acid was found as $500 \mathrm{~g} \mathrm{~L}^{-1}$ in the optimum conditions at $400 \mathrm{~K}$ temperature, $4 \mathrm{~min}$ dynamic time and $28 \mathrm{~min}$ static time. Approximation models were employed for determining solubility of sebacic acid at elevated temperatures.
\end{abstract}

Keywords Dicarboxylic acid - Hot water solubility . Box-Behnken design - Sebacic acid · Response surface methodology

\section{Introduction}

Subcritical water has been gaining researchers' attention due to its non-toxic, non-flammable, non-explosive properties $[1,2]$. Subcritical water has variable physical properties compared to water at ambient conditions such as dielectric constant, which is typically used for measuring polarity and can easily be altered by changing temperature and pressure $[3,4]$. Increasing the temperature above 373

E. Yabalak $(\bowtie)$ · Ö. Görmez · B. Gözmen · A. M. Gizir Department of Chemistry, Faculty of Arts and Science, Mersin University, 33343 Mersin, Turkey

e-mail: yabalakerdal@gmail.com

E. Yabalak · A. M. Gizir

Advanced Technology Research and Application,

Mersin University, 33343 Mersin, Turkey and $423 \mathrm{~K}$, the dielectric constant of water can be likened to dimethyl sulfoxide and acetonitrile, respectively [5-7]. The solubility of analytes in subcritical water is reasonably needed which constitutes base date in green subcritical technology, such as subcritical water extraction and chromatography [8]. Subcritical water has been used in various applications such as decomposition and degradation of waste materials [9], extraction of heavy metals [10], dissolve less soluble or insoluble materials and valuable substances [11-15] for the last decades.

Dicarboxylic acids are widely used as a raw material in production process of plasticizers, dyes, inks, adhesive, lubricant, cosmetics, biodegradable polymers, food and pharmaceutical industries [16-21]. Biodegradable polymers have been used as an alternative instead of nondegradable plastics which accumulate in soil and cause pollution [22]. Biodegradable polymers reduce the risk of accumulation of plastic materials in the environment and the cost of waste management of production and usage process [23].

Sebacic acid and its derivatives have been widely applied in biomedical applications for drug delivery devices, wound dressings, orthopedic fixation devices, temporary vascular grafts, different types of tissue-engineered grafts [24-28], etc. Sebacic acid (decanedioic acid, $\mathrm{C}_{10} \mathrm{H}_{18} \mathrm{O}_{4}$, CAS No: 111-20-6) is one of the most used biodegradable plastics monomer.

There are few quantitative data on the aqueous solubility of sebacic acid in the literature [29]. Aqueous solubility data of the sebacic acid are of increasing interest and significance. There are several conventional studies based on using organic solvents and solvent mixtures to determine the solubility of sebacic acid [30]. These methods may be useful to determine the yield and purity of sebacic acid, but the organic solvents used are often toxic and these methods 
required removal step of solvent. In addition, solvent removal is expensive and time-consuming [6]. There is no difficulty in using subcritical water as a solvent, which is exposed in the traditional methods. Enhancing the solubility of sebacic acid in water is important due to the widespread production of it. The water solubility of sebacic acid at 50 and $60{ }^{\circ} \mathrm{C}$ is 2.2 and $4.2 \mathrm{~g} \mathrm{~L}^{-1}$, respectively [29].

The response surface methodology (RSM) is an advantageous method to evaluate the performance of a system by varying the variables and their interactions effects and carrying out a limited number of experiments [31]. The response of interest is influenced by several variables during RSM and the main goal is to optimize this response [32].

RSM was used for studying the effect of variables such as temperature $(\mathrm{K})$, static and dynamic time $(\mathrm{min})$ on the solubility of sebacic acid $\left(\mathrm{g} \mathrm{L}^{-1}\right)$ to influence the maximum benefit for dissolving more sebacic acid in optimum conditions. The solubility experiment was performed at moderate temperatures ranging from 313 to $433 \mathrm{~K}$ with 50 bar pressure to keep water in liquid state under varied static and dynamic extraction time.

We aimed to investigate the solubility of sebacic acid in order that offering a model for removing it from contaminated sites and recover it by further precipitation step.

\section{Experimental}

\section{Materials}

Sebacic acid (purity $\geq 98 \%$ ), HPLC grade methanol (purity $\geq 99.8 \%$ ), triethylamine (purity $\geq 99 \%$ ) and 2-bromoacetophenone (purity $\geq 98 \%$ ) were purchased from Merck (Darmstadt, Germany). Ultra-pure water was prepared in our laboratory using a Millipore Milli-Q Advantage A10.

Apparatus and procedures

A special stainless steel cylindrical HPLC column (100 $\mathrm{mm} \times 5 \mathrm{~mm}$ i.d.) was used as equilibration cell for solubility experiments. The column was filled with $1.25 \mathrm{~g}$ sebacic acid. Both ends of the column covered with $0.45 \mu \mathrm{m}$ mesh size frits and cell were tightened to prevent leakage of particulates. A preheating coil was placed in front of the equilibration cell. Thus, required subcritical water which passed through the cell along the experiment provided (Fig. 1). The loaded cell was placed in the Teknosem TF R 400 model oven to provide precise temperature control $(0.1 \mathrm{~K})$ during the solubility determination (Fig. 1). A Teledyne ISCO $260 \mathrm{D}$ series syringe pump system (Lincoln, NE, USA) was used to deliver water and supply pressure at 50 bars in the constant pressure mode.

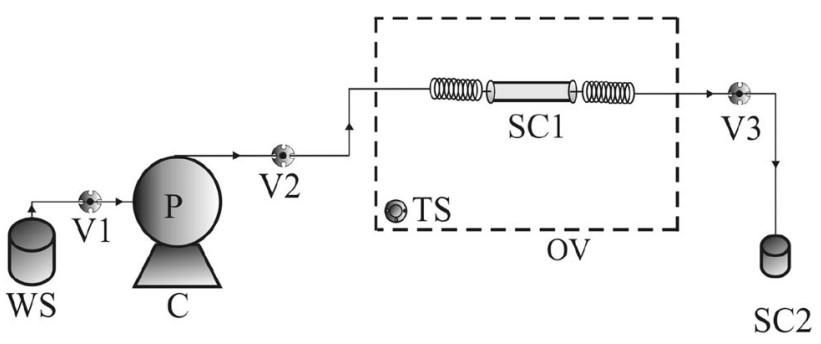

Fig. 1 Diagram of the solubility apparatus. $P$ isco $260 \mathrm{D}$ syringe pump, $C$ control unit, $W S$ water supply, $T S$ temperature sensor, $S C 1$ solubility equilibrium cell, $V 1-V 3$ valves, $S C 2$ solution collector, $O V$ teknosem TF R 400 oven

Pre-experiments were performed to select the maximum temperature. It was obtained that $1.45 \pm 0.18 \%$ of initial amount of sebacic acid was degraded at $453 \mathrm{~K}$. Thus, experiments were performed at three different temperatures ranging from 313 to $433 \mathrm{~K}$, three dynamic time modes (2, 4 and $6 \mathrm{~min})$ and three static time modes (10, 20 and $30 \mathrm{~min}$ ) using RSM to ensure the reliability of the experimental solubility data. To achieve set temperature inside equilibration cell, oven was heated slowly to the beginning of the static time. After the static time at which the solute (sebacic acid) and solvent (subcritical water) reach to equilibrium in the equilibration cell, dynamic mode was started and fractions were collected during this mode in each experiment. To diminish the carryover effect (such as repulsion of solute-solvent), valve 2 was closed after every experiment (Fig. 1). Fractions (approximately $2.5 \mathrm{~mL}$ ) of the heated water-acid solution were collected and $2.5 \mathrm{~mL}$ of methanol was added to the solution to dissolve obtained sebacic acid at room temperature. The mixtures were then analyzed by high-performance liquid chromatography.

\section{Experimental design}

In the present study, the Box-Behnken design (BBD) was employed for the optimization of solubility of sebacic acid by subcritical water. Three main operating parameters (the three factors with three levels) were chosen as independent variables: temperature (K) $x_{1}$; static $x_{2}$ and dynamic time (min) $x_{3}$ also solubility $\left(\mathrm{g} \mathrm{L}^{-1}\right)(Y)$ was assumed as the dependent variable (response). Each independent variable was coded at three levels $-1,0$ and +1 . The three-factor Box-Behnken design has 17 runs and is presented in Table 1. Each solubility experiment was done in triplicates; average and standard deviation of each experimental value are presented in Table 1.

Derivatization procedure and HPLC analysis

One milli liter of analyte solution (maximum containment: $0.0125 \mathrm{~g} \mathrm{~mL}^{-1}$ of sebacic acid), $75 \mu \mathrm{L}$ of 
Table 1 The three-factor BoxBehnken design and the value of the response function

\begin{tabular}{llllc}
\hline $\begin{array}{l}\text { Experiment } \\
\text { number }\end{array}$ & Temperature $(\mathrm{K})$ & Static time (min) & Dynamic time (min) & Solubility $\left(\mathrm{g} \mathrm{L}^{-1}\right.$ water) \\
\hline 1 & $313(-1)$ & $10(-1)$ & $4(0)$ & $6.9 \pm 0.2$ \\
2 & $433(+1)$ & $10(-1)$ & $4(0)$ & $296.3 \pm 7.1$ \\
3 & $313(-1)$ & $30(+1)$ & $4(0)$ & $8.5 \pm 0.4$ \\
4 & $433(+1)$ & $30(+1)$ & $4(0)$ & $456.8 \pm 8.3$ \\
5 & $313(-1)$ & $20(0)$ & $2(-1)$ & $7.1 \pm 0.3$ \\
6 & $433(+1)$ & $20(0)$ & $2(-1)$ & $314.2 \pm 5.5$ \\
7 & $313(-1)$ & $20(0)$ & $6(+1)$ & $7.3 \pm 0.3$ \\
8 & $433(+1)$ & $20(0)$ & $6(+1)$ & $373.5 \pm 10.1$ \\
9 & $373(0)$ & $10(-1)$ & $2(-1)$ & $188.2 \pm 5.2$ \\
10 & $373(0)$ & $30(+1)$ & $2(-1)$ & $464.2 \pm 7.7$ \\
11 & $373(0)$ & $10(-1)$ & $6(+1)$ & $252.4 \pm 5.2$ \\
12 & $373(0)$ & $30(+1)$ & $6(+1)$ & $484.3 \pm 9.6$ \\
13 & $373(0)$ & $20(0)$ & $4(0)$ & $429.3 \pm 13.1$ \\
14 & $373(0)$ & $20(0)$ & $4(0)$ & $468.3 \pm 8.8$ \\
15 & $373(0)$ & $20(0)$ & $4(0)$ & $402.6 \pm 20.7$ \\
16 & $373(0)$ & $20(0)$ & $4(0)$ & $470.2 \pm 6.9$ \\
17 & $373(0)$ & $20(0)$ & $4(0)$ & $487.5 \pm 12.1$ \\
\hline
\end{tabular}

\begin{tabular}{lllcll}
\hline Source & Sum of squares & Degrees of freedom & Mean square & $F$ value & $P$ value prob $>F$ \\
\hline Model & $5.476 \times 10^{5}$ & 9 & $6,0841.60$ & 20.92 & 0.0003 \\
Residual & $2,0355.50$ & 7 & $2,907.93$ & - & - \\
Lack of fit & $1,5538.90$ & 3 & $5,179.62$ & 4.30 & 0.0963 \\
Pure error & $4,816.64$ & 4 & $1,204.16$ & - & - \\
\hline
\end{tabular}

Table 2 ANOVA results of quadratic model

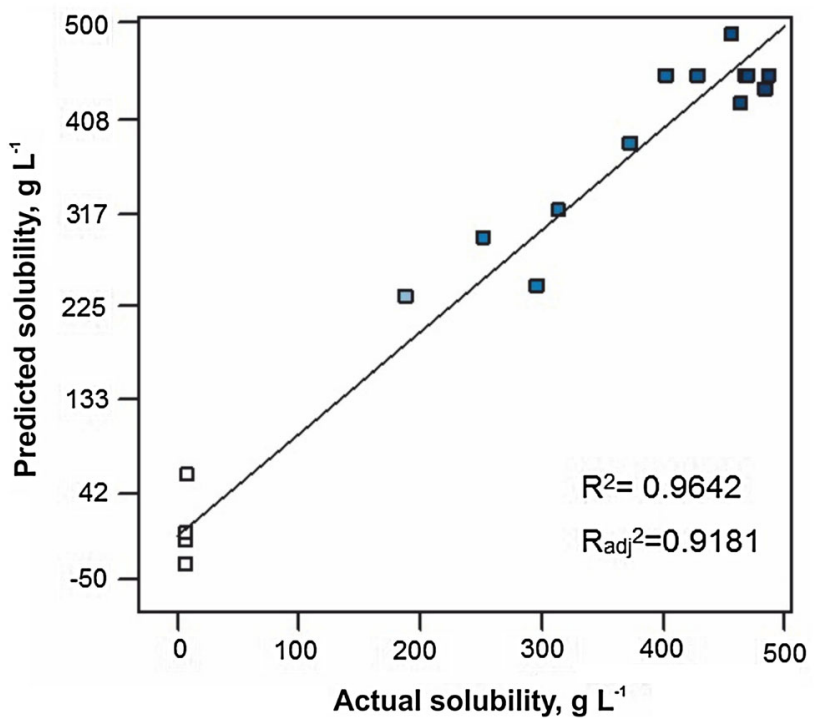

Fig. 2 The actual and predicted plot of the solubility of sebacic acid

$$
\begin{aligned}
Y= & \beta_{0}+\beta_{1} x_{1}+\beta_{2} x_{2}+\beta_{3} x_{3}+\beta_{12} x_{1} x_{2}+\beta_{13} x_{1} x_{3} \\
& +\beta_{23} x_{2} x_{3}+\beta_{11} x_{1}^{2}+\beta_{22} x_{2}^{2}+\beta_{33} x_{3}^{2}+e_{i}
\end{aligned}
$$

where $Y$ is the response, $x_{i}$ and $x_{j}$ are the coded variables, $\beta_{0}$ is the constant coefficient, $\beta_{j}, \beta_{j j}$ and $\beta_{i j}$ the first-order, 
Fig. 3 a The effects of static time and temperature on the solubility of sebacic acid in subcritical water at constant dynamic time. b The effects of dynamic time and temperature on the solubility of sebacic acid in subcritical water at constant static time. c The effects of dynamic time and static time on the solubility of sebacic acid in subcritical water at constant temperature

quadratic and interaction effects, respectively, $i$ and $j$ are the index numbers for factor, and $e_{i}$ is the residual error [33, 34].

The approximating function of solubility obtained by Design-Expert software [35] is given in Eq. (2).

$$
\begin{aligned}
Y= & +451.58+176.38 x_{1}+83.75 x_{2}+17.95 x_{3} \\
& +39.75 x_{1} x_{2}+14.77 x_{1} x_{3}-11.02 x_{2} x_{3} \\
& -215.61 x_{1}^{2}-43.85 x_{2}^{2}-60.45 x_{3}^{2}
\end{aligned}
$$

In Eq. (2), $Y$ corresponds to the response of solubility of sebacic acid by subcritical water system; $x_{1}, x_{2}, x_{3}$ correspond to independent variable of temperature, static and dynamic time, respectively. For solubility of sebacic acid coefficients of all the factors showed positive correlation and the temperature $\left(x_{1}\right)$ is the most effective factor for the solubility. This factor $\left(x_{1}\right)$ is followed by static $\left(x_{2}\right)$ and dynamic time $\left(x_{3}\right)$. Also, two-variable interaction temperature-static time $\left(x_{1} x_{2}\right)$ has been demonstrated to be the crucial factors for solubility of sebacic acid. Dynamic time remains low when compared with other positive effects.

Analysis of variance (ANOVA) result of this quadratic model is presented in Table 2. The coefficient of variation (CV) and adequate precision were 17.9 and 12.6, respectively. If adequate precision value in other word signal to noise ratio is greater than four, then adequate precision would be obtained [36].

The predicted values for the solubility of sebacic acid versus experimental ones showed that experimental values were distributed near to the straight line in Fig. 2. This distribution is supported by the values obtained, $R^{2}$ and $R_{\text {adj }}^{2}$, in Table 2. The $R^{2}$ value was 0.9642 and adjusted $R^{2}$ was 0.9181 . The high $R^{2}$ values indicate that the model is significant (Fig. 2).

Figure 3 shows the effects of independent variable on the solubility of sebacic acid with subcritical water. When dynamic time was kept constant at $4.0 \mathrm{~min}$, the effects both static time and temperature are tested in Fig. 3a. Effective dissolution occurred at temperatures above $373 \mathrm{~K}$, but began to decline above $410 \mathrm{~K}$ due to degradation of sebacic acid. Also, static time of
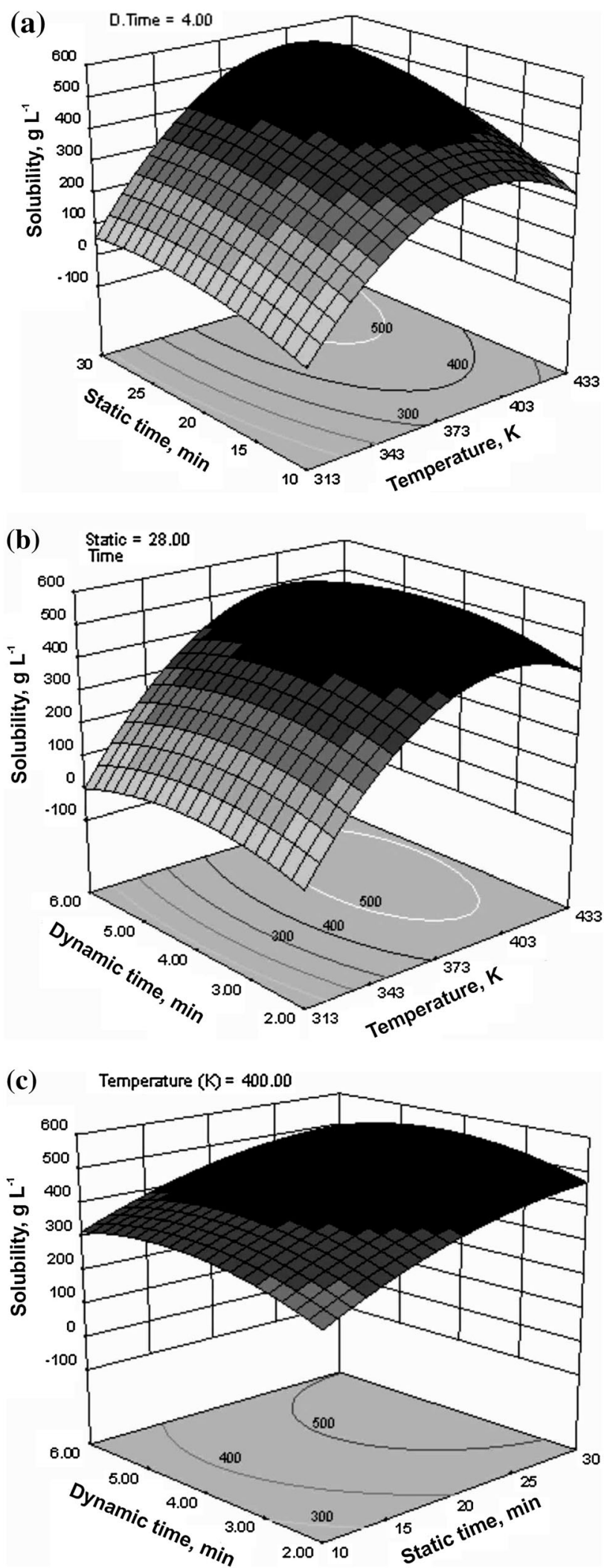
extraction must be kept for at least 20 min for effective solubility. The influence of temperature and dynamic time investigated when the static time is kept constant at 28 min as shown in Fig. 3b. It can be seen from Fig. 3b that dynamic time was not very effective variable in the range of 2-6 min for solubility experiments. The maximum solubility of sebacic acid with subcritical water was observed at $400 \mathrm{~K}$, which increased the solubility to $500 \mathrm{~g} \mathrm{~L}^{-1}$ (Fig. 3c).

The effects of all the independent variables on the solubility of sebacic acid at the optimal run conditions in the design space are compared in the perturbation plot (Fig. 4). When this perturbation plot is analyzed it was seen that to provide an effective resolution of sebacic acid, temperature, static and dynamic time were kept constant at $400 \mathrm{~K}$, 28 and $4 \mathrm{~min}$, respectively.

\section{Approximation models}

There are a few approximation models to predict solubility of organic molecules reported in the literature. One of these models which offered by Miller et al. [37] was used to

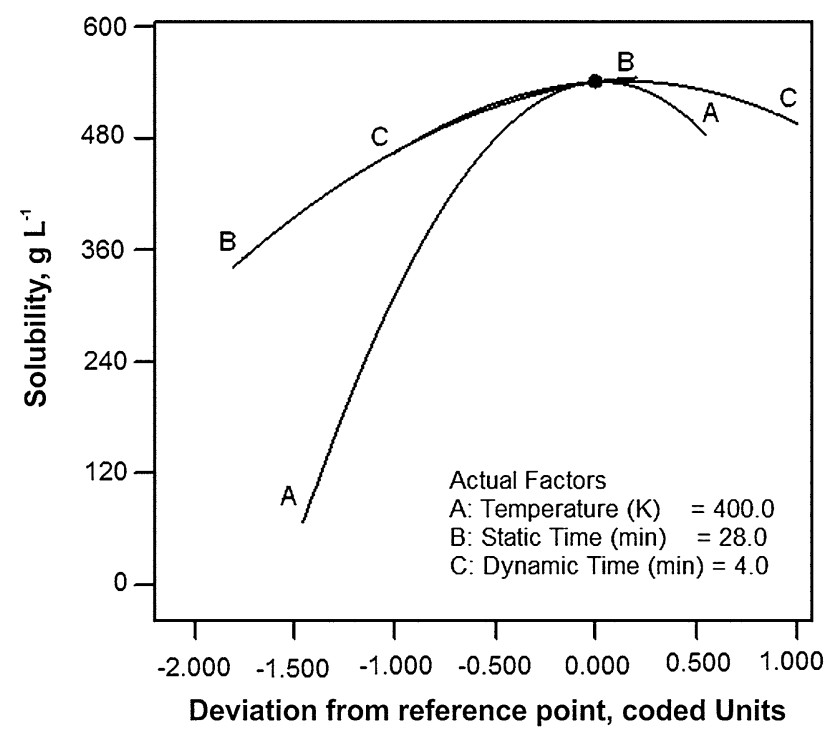

Fig. 4 Perturbation plot for solubility of sebacic acid with subcritical water predict mole fraction of solubility of polycyclic aromatic hydrocarbons in high-temperature water. As indicated in Eq. (3), the mole fraction of solubility at ambient temperature $\left(T_{0}\right)$ can be predicted with the knowledge of the mole fraction of solubility at higher temperatures.

$\ln x_{2}(T) \approx\left(\frac{T_{0}}{T}\right) \ln x_{2}\left(T_{0}\right)$

Miller et al. [36] modified Eq. (3) and obtained Eq. (4) for the mole fraction solubility at $T$ as follows:

$\ln x_{2}(T)=\left(\frac{T_{0}}{T}\right) \ln x_{2}\left(T_{0}\right)+15\left(\frac{T_{0}}{T}-1\right)^{3}$

To predict the solubility of liquid nonpolar organic compounds in subcritical water, Mathis et al. [37] modified Eq. (3) using the following equation:

$\ln x_{2}(T)=\left(\frac{T_{0}}{T}\right) \ln x_{2}\left(T_{0}\right)+2\left(\frac{T-T_{0}}{T_{0}}-1\right)^{3}$

Kayan et al. [38] achieved a better approximation model for the solubility prediction of the organic acids in subcritical water using Eq. (6).

$\ln x_{2}(T)=\left(1.85 \frac{T_{0}}{T}-1\right) \ln x_{2}\left(T_{0}\right)$

The experimental data in comparison with the predicted values obtained by Eqs. (3)-(6) were summarized in Table 3. Although, Eqs. (3)-(5) failed to predict the correct values, Eq. (6) which was previously modified by Kayan et al. [39] showed better prediction for the solubility of sebacic acid.

\section{Conclusions}

The results of this study demonstrate that the Box-Behnken design methodology could efficiently optimize solubility of the sebacic acid with subcritical water, using a homemade system. It was found that temperature and static time are effective parameters on the solubility of the sebacic acid. The solubility of sebacic acid was found as $500 \mathrm{~g} \mathrm{~L}^{-1}$ at optimum values of temperature, static time and dynamic time such as $400 \mathrm{~K}, 28$ and 4 min, respectively. Experimental results show a good consistency with
Table 3 Comparison of experimental mole fraction of solubility $x_{2}$ for sebacic acid (2) in water (1) with predict values using Eqs. (3)-(6)

\begin{tabular}{lllllc}
\hline $10^{3} x_{2}$ & & & & \\
\hline $\mathrm{T} / \mathrm{K}$ & Experimental & Equation (3) & Equation (4) & Equation (5) & Equation (6) \\
\hline 298 & $0.02225 \pm 0.00814$ & 0.022250 & 0.02225 & 0.003011 & 0.1110 \\
313 & $0.61360 \pm 0.01317$ & 0.037170 & 0.03724 & 0.006702 & 0.2868 \\
373 & $16.47000 \pm 0.38850$ & 0.191600 & 0.24330 & 0.082850 & 5.9600 \\
433 & $25.69000 \pm 0.41500$ & 0.627200 & 2.52500 & 0.452000 & 53.4000 \\
\hline
\end{tabular}


approximation model developed for the organic acids (Eq. 6), which is based on simplifying assumptions in relation with previously reported works.

Acknowledgments This work was supported by Mersin University Research Fund (Project No: BAP-FEF KB (BG) 2010-4 A).

Open Access This article is distributed under the terms of the Creative Commons Attribution License which permits any use, distribution, and reproduction in any medium, provided the original author(s) and the source are credited.

\section{References}

1. Rogalinski T, Liu K, Albrecht T, Brunner G (2008) Hydrolysis kinetics of biopolymers in subcritical water. J Supercrit Fluids 46:335-341

2. Carr AG, Branch A, Mammucari R, Foster NR (2010) The solubility and solubility modelling of budesonide in pure and modified subcritical water solutions. J Supercrit Fluids 55:37-42

3. Fernández-Prini RJ, Corti HR, Japas ML (1991) High-temperature aqueous solutions: thermodynamic properties. CRC Press, Boca Raton

4. Shaw RW, Brill TB, Clifford AA, Eckert CA, Franck EU (1991) Supercritical water: a medium for chemistry. Chem Eng News 69:26-39

5. IAPWS (1997) Release on the static dielectric constant of ordinary water substance for temperatures from $238 \mathrm{~K}$ to $873 \mathrm{~K}$ and pressures up to $1000 \mathrm{MPa}$. http://www.iapws.org/

6. Smith RM, Burgess RJ (1996) Superheated water: a clean eluent for reversed-phase high-performance liquid chromatography. Anal Commun 33:327-329

7. Carr AG, Mammucari R, Foster NR (2011) A review of subcritical water as a solvent and its utilisation for the processing of hydrophobic organic compounds. Chem Eng J 172:1-17

8. Kapalavavi B, Ankney J, Baucom M, Yang Y (2014) Solubility of parabens in subcritical water. J Chem Eng Data 59:912-916

9. Kayan B, Gözmen B (2012) Degradation of acid red 274 using $\mathrm{H}_{2} \mathrm{O}_{2}$ in subcritical water: application of response surface methodology. J Hazard Mater 201-202:100-106

10. Yabalak E, Gizir AM (2013) Subcritical and supercritical fluid extraction of heavy metals from sand and sewage sludge. J Serb Chem Soc 78:1013-1022

11. Alwyn GD (1995) Comprehensive organometallic chemistry II. BPC Wheatons Ltd, London

12. Walsum GP, Shi H (2004) Carbonic acid enhancement of hydrolysis in aqueous pretreatment of corn stover. Bioresour Technol 93:217-226

13. Yoshida H, Tavakoli O (2004) Sub-critical water hydrolysis treatment for waste squid entrails and production of amino acids, organic acids, and fatty acids. J Chem Eng Jpn 37:253-260

14. Baig MN, Zetzl C, Brunner G (2005) In: Perrut M (ed) Proceedings of the 10th european meeting on supercritical fluids. France, Strasbourg/Colmar, pp 12-14

15. Rogalinski T, Herrmann S, Brunner G (2005) Production of amino acids from bovine serum albumin by continuous subcritical water hydrolysis. J Supercrit Fluids 36:49-58

16. Williams AE (1978) In: Mark HF, Othmer DF, Overberger CG, Seaborg GT (Eds) Kirk-Othmer encyclopedia of chemical technology. Wiley, New York, pp 778

17. Opgrande JL, Dobratz CJ, Brown EE, Liang JC, Conn GS, Wirth J, Shelton J (1992) In: Kroschwitz JI, Howe-Grant M (Eds) Kirk- othmer encyclopedia of chemical technology, Wiley, New York, pp 103

18. Budavari S (1996) The merck index: an encyclopedia of chemicals, drugs and biologicals. Merck Co., Inc., Whitehouse Station

19. Bretti C, Crea F, Foti C, Sammartano S (2006) Solubility and activity coefficients of acidic and basic nonelectrolytes in aqueous salt solutions. 2. Solubility and activity coefficients of suberic, azelaic, and sebacic acids in $\mathrm{NaCl}(\mathrm{aq}),\left(\mathrm{CH}_{3}\right)_{4} \mathrm{NCl}(\mathrm{aq})$, and $\left(\mathrm{C}_{2} \mathrm{H}_{5}\right)_{4} \mathrm{NI}(\mathrm{aq})$ at different ionic strengths and at $\mathrm{t}=25^{\circ} \mathrm{C}$. J Chem Eng Data 51:1660-1667

20. Xia Q, Chen SN, Chen YS, Zhang MS, Zhang FB, Zhang GL (2011) Solubility of decanedioic acid in binary solvent mixtures. Fluid Phase Equilib 304:105-109

21. Park HS, Seo J, Lee HY, Kim HW, Wall IB, Gong MS, Knowles JC (2012) Synthesis of elastic biodegradable polyesters of ethylene glycol and butylene glycol from sebacic acid. Acta Biomaterilia 8:2911-2918

22. Siotto M, Tosin M, Innocenti FD, Mezzanote V (2011) Mineralization of monomeric components of biodegradable plastics in preconditioned and enriched sandy loam soil under laboratory conditions. Water Air Soil Pollut 221:245-254

23. Tokiwa Y, Calabia BP, Ugwu CU, Aiba S (2009) Biodegradability of plastics. Int J Mol Sci 10:3722-3742

24. Dang WB, Daviau T, Brem H (1996) Morphological characterization of polyanhydride biodegradable implant GLIA$\operatorname{DEL}(\mathrm{R})$ during in vitro and in vivo erosion using scanning electron microscopy. Pharm Res 13:683-691

25. Boateng JS, Matthews KH, Stevens HNE, Eccleston GM (2008) Wound healing dressings and drug delivery systems: a review. J Pharm Sci 97:2892-2923

26. Cotton NJ, Egan MJ, Brunelle JE (2008) Composites of poly(DLlactide-co-glycolide) and calcium carbonate: in vitro evaluation for use in orthopedic applications. J Biomed Mater Res Part A 85:195-205

27. Madsen J, Armes SP, Bertal K, Lomas H, MacNeil S, Lewis AL (2008) Biocompatible wound dressings based on chemically degradable triblock copolymer hydrogels. Biomacromolecules 9:2265-2275

28. Liang Y, Xiao L, Zhai Y, Xie C, Deng L, Dong A (2013) Preparation and characterization of biodegradable poly(sebacic anhydride) chain extended by glycol as drug carrier. J Appl Polym Sci 127:3948-3953

29. Yalkowsky SH, He Y (2003) Handbook of aqueous solubility data. CRC Press, Cleveland

30. Xia Q, Zhang FB, Zhang GL, Ma JC, Zhao L (2008) Solubility of sebacic acid in binary water plus ethanol solvent mixtures. J Chem Eng Data 53:838-840

31. Singh KP, Singh AK, Gupta S, Sinha S (2011) Optimization of $\mathrm{Cr}(\mathrm{VI})$ reduction by zero-valent bimetallic nanoparticles using the response surface modeling approach. Desalination 270:275-284

32. Zahed MA, Aziz HA, Isa MH, Mohajeri L (2012) Response surface analysis to improve dispersed crude oil biodegradation. Clean-Soil Air Water 40:262-267

33. Montgomery DC (1996) Design and analysis of experiments. Wiley, New Jersey

34. Myers RH, Montgomery DC (2002) Response surface methodology: process and product optimization using designed experiments. Wiley, New Jersey

35. Design-Expert Software Version 8.0.7.1, Stat-Ease, 2021 East Hennepin ave, suite 480 Minneapolis, MN 55413

36. Körbahti BK, Rauf MA (2008) Response surface methodology (RSM) analysis of photoinduced decoloration of toludine blue. Chem Eng J 136:25-30

37. Miller DJ, Hawthorne SB, Gizir AM, Clifford AA (1998) Solubility of polyacyclic aromatic hydrocarbons in subcritical water from 298 to 498 K. J Chem Eng Data 43:1043-1047 
38. Mathis J, Gizir AM, Yang Y (2004) Solubility of alkylbenzenes and a model for predicting the solubility of liquid organics in high-temperature water. J Chem Eng Data 49:1269-1272
39. Kayan B, Yang Y, Lindquist JE, Gizir AM (2010) Solubility of benzoic and salicylic acids in subcritical water at temperatures ranging from (298 to 473) K. J Chem Eng Data 55:2229-2232 